\title{
Age-Dependent Effect of Long-Term Microwave Radiation on Postnatal Neurogenesis in Rats: Morphological and Behavioral Study
}

\author{
A. RAČEK ${ }^{1}$, K. BEŇOVÁ ${ }^{1}$, P. ARNOUL ${ }^{2}$, M. ZÁVODSKÁ ${ }^{2}$, A. ANGELIDIS ${ }^{2}$, \\ V. CIGÁNKOVÁ ${ }^{1}$, V. ŠIMAIOVÁ ${ }^{1}$, E. RAČEKOVÁ ${ }^{2}$ \\ ${ }^{1}$ Department of Genetics and Biology, University of Veterinary Medicine and Pharmacy, Košice, \\ Slovak Republic, ${ }^{2}$ Institute of Neurobiology, Slovak Academy of Sciences, Košice, Slovak \\ Republic
}

Received August 24, 2017

Accepted January 5, 2018

On-line March 12, 2018

\section{Summary}

Processes of adult neurogenesis can be influenced by environmental factors. Here, we investigated the effect of microwave radiation (MWR) on proliferation and cell dying in the rat rostral migratory stream (RMS) - a migration route for the neuroblasts of the subventricular zone. Adult and juvenile (two weeks old) rats were exposed to a pulsed-wave MWR at the frequency of $2.45 \mathrm{GHz}$ for 1 or $3 \mathrm{~h}$ daily during 3 weeks. Adult rats were divided into two groups: without survival and with two weeks survival after irradiation. Juvenile rats survived till adulthood, when were tested in the light/dark test. Proliferating cells in the RMS were labeled by Ki-67; dying cells were visualized by Fluoro-Jade $C$ histochemistry. In both groups of rats irradiated as adults we have observed significant decrease of the number of dividing cells within the RMS. Exposure of juvenile rats to MWR induced only slight decrease in proliferation, however, it strikingly affected cell death even two months following irradiation. In addition, these rats displayed locomotor hyperactivity and decreased risk assessment in adulthood. Our results suggest that the long-lasting influence of radiation is manifested by affected cell survival and changes in animals' behavior.

\section{Key words}

Adult neurogenesis - Microwave radiation - Proliferation - Cell death $\bullet$ Rostral migratory stream

\section{Corresponding author}

A. Raček, Department of Genetics and Biology University of Veterinary Medicine and Pharmacy, Komenského 73, 04181 Košice, Slovak Republic. E-mail: racekadam@gmail.com

\section{Introduction}

During the last decades, our environment has become increasingly polluted by non-ionizing electromagnetic radiation, produced by electronic devices, particularly mobile phones and personal wireless devices. Microwave radiation (MWR) from the mobile phone base stations is regarded as having low power. However, as the output is continual, it is practically unavoidable (Khurana et al. 2010). Unfortunately, new telecommunication technologies have been introduced without consideration of their possible health risk on living organisms. Epidemiological and animal studies have only emerged following the introduction and widespread use of these technologies (Orendáčová et al. 2007, Altunkaynak et al. 2016). Several studies have investigated the effects of microwave exposure on brain physiology and morphology, as a sensitive target organ for MWR. Because of the lack of a reliable animal model that would ensure defined exposure parameters, it is difficult to directly compare experimental results and to draw definitive conclusions. On the other hand, the majority of existing results have shown that the increased exposure to electromagnetic radiation may lead to hazardous effects on the brain (Vojtísek et al. 2009, Hao et al. 2015), suggesting the need for further research in this field.

The most frequently investigated brain structures are the cortex, basal ganglia, hippocampus and cerebellum, where neuronal damage and cellular loss have been evaluated (Odaci et al. 2008, Finnie et 
al. 2009). In addition, recent research of the effect of MWR is increasingly focused on the areas of adult neurogenesis, i.e. the brain regions where production of new neurons takes place in adulthood. The main neurogenic region in the adult mammalian brain is the subventricular zone (SVZ), located in the wall of the lateral brain ventricle. Precursor cells that originate in the SVZ extensively migrate a long distance (about $8 \mathrm{~mm}$ in rats) along the rostral migratory stream (RMS) toward the olfactory bulb (OB) (Lois and AlvarezBuylla 1994). During their migration within the RMS, the neuroblasts maintain the ability to divide (Menezes et al. 1995) and they can also undergo apoptosis (Brunjes and Armstrong 1996). In the OB the progenitor cells differentiate into two major types of interneurons, the granule and periglomerular cells (Luskin 1993). The functional role of new interneurons has been confirmed in the modulation of activity of major output neurons in the OB (Lledo et al. 2008). The generation of new neurons in the olfactory neurogenic area consists of multiple steps, such as proliferation, migration, differentiation and integration of neuronal progenitor cells. These highly dynamic processes are regulated by many physiological factors and importantly, they can also be influenced by different environmental cues. Additionally, recent evidence has shown that the neurogenesis in the SVZ-RMS-OB system is altered in various neurodegenerative diseases, suggesting a close link between the pathogenesis of these diseases and anomalies in olfactory neurogenesis (Winner et al. 2011).

Among the environmental factors investigated in relation to adult neurogenesis, the effect of MWR, even short lasting, appears to be one of the most serious (Orendáčová et al. 2011). As the effects of chronic irradiation on neurogenesis remain largely unknown, the aim of this study was to investigate morphological and functional consequences of long-term exposure to MWR in adult and juvenile rats by the analysis of proliferation activity and the death of cells in the RMS. While stress-induced alterations in neurogenesis and behavior that occur during adulthood are largely reversible, the changes induced by early life stress are generally longer lasting, and the consequences often persist throughout the life (Korosi et al. 2012). Therefore, our next goal was to study the MWR effect on the behavior of animals that were irradiated as juvenile and allowed to survive till adulthood.

\section{Methods}

\section{Animals and experimental design}

The study was carried out on male Wistar albino rats, which were divided into two main groups: adult (3 months old) and juvenile (two weeks old at the beginning of experiment) rats. Within the group of adult rats, two subgroups were created regarding the survival time after the exposure to MWR: without survival and with two weeks survival. Pilot experiments showed no differences between sham-exposed and control rats for all data parameters investigated. Thus, in the present experiment only sham-exposed rats were used as controls, which underwent the same procedures as irradiated animals, except for the MWR exposure. The controls matched the age of irradiated rats ( $\mathrm{n}=10$ in each group).

Experimental protocols were approved by the Institutional Ethical Committee, in accordance with current Slovak Republic legislation.

\section{Experimental intervention}

Both groups of rats were exposed whole body to a pulsed-wave EMR at the frequency of $2.45 \mathrm{GHz}$ and mean power density of $2.8 \mathrm{~mW} / \mathrm{cm}^{2}$, at an average specific absorption rate (SAR) of $5.24 \mathrm{~W} / \mathrm{kg}$ in a purposedesigned exposure chamber. The exposure system and spectral analysis have been previously described (Orendáčová et al. 2009). Homogeneity of the emitted electromagnetic field (EMF) inside the chamber was mapped with a spectral analyzer at various EMF modes of the microwave emitter. During irradiation freely moving adult rats and juvenile rats with the mother remain in their home cages. Adult rats were irradiated for $3 \mathrm{~h}$ daily during 3 weeks and juvenile rats for $1 \mathrm{~h}$ daily during 3 weeks.

After the exposure to MWR, one subgroup of adult rats was housed under normal condition for 2 weeks to provide a recovery period, and the group of juvenile rats was allowed to survive through to adulthood.

\section{Behavioral testing}

The rats irradiated as juvenile, after reaching adulthood, and age matched sham-exposed rats were tested in the light/dark test - a variation of the open field test, which is widely used for an assessment of locomotor activity and emotional reactivity in rodents. The apparatus consisted of a white laminate-walled square arena with a black wooden hide box placed on the right side of the arena - light compartment. The animals were 
individually placed inside the wooden hide box for $5 \mathrm{~min} /$ test. They could pass inside or outside the hide box through a closable hole placed at the center of the front wall of the box. During the testing period, the experimenter stayed outside the testing room. Subsequent video analysis by an observer blind to group assignment scored the rat's latency to emerge from the hide box, the duration of time spent in the light compartment and in the hide box, the number of head outs and defecation. Risk assessment behavior was also scored which refers to the time the rats spent with their head poking out of the hide box but with the rest of their body concealed inside the box. After each session, the apparatus was cleaned with a damp sponge to remove any trace of odor.

The behavior was recorded using a video tracking system (EthoVision XT7, NOLDUS, The Netherlands). Statistical analysis was performed using unpaired Student's t-test.

\section{Histological procedures}

Both control and irradiated rats were deeply anesthetized with chloral hydrate and perfused transcardially with a solution of $4 \%$ paraformaldehyde in $0.1 \mathrm{M}$ phosphate buffer. $30 \mu \mathrm{m}$ thick sagittal brain sections were cut on the cryostat and processed for immunohistochemical and histochemical labeling.

Proliferating cells were immunohistochemically labelled by the endogenous marker of proliferation Ki-67. Briefly, the sections were incubated with the rabbit anti Ki-67 antibody (1:1,000, Abcam, Cambridge, MA, USA) at the room temperature for $18 \mathrm{~h}$. As the secondary antibody biotinylated goat anti-rabbit $\mathrm{IgG}$ (1:200, Santa Cruz, CA, USA) was used for $2 \mathrm{~h}$, followed by the ABC kit (Vector, CA, USA) and DAB substrate for visualization of Ki-67 positive cells. The sections were examined by light microscope (Olympus BX51) fitted with an Olympus DP71 digital camera system.

To label dying cells, Fluoro-Jade C (FJ-C; Histo-Chem Inc., AR, USA) histochemistry has been used. Sections were mounted on gelatine coated slides and air dried at $50{ }^{\circ} \mathrm{C}$. Subsequently the slides were immersed in absolute alcohol, $70 \%$ alcohol, distilled water and treated with $0.06 \%$ potassium permanganate. Then the slides were incubated in Fluoro-Jade $\mathrm{C}$ solution ( $1 \mu \mathrm{g} / \mathrm{ml}$ in $0.1 \%$ acetic acid) for $30 \mathrm{~min}$, dried at room temperature, cleared in xylene and cover- slipped with DPX. The sections were analyzed using Olympus Reflected Fluorescence system U-RFL-T, the Olympus BX51 and Olympus DP71 digital camera.

\section{Quantification}

For quantitative analysis only those section were used where the whole extent of the RMS was visible (6-8 sections/hemisphere). In order to obtain detailed picture on cell proliferation quantitative analysis of Ki-67 positive cells were provided in three specific parts of the RMS - in the vertical arm, elbow and the horizontal arm. Proliferating cells were counted using the Disector software version 2.0 (Tomori et al. 2001). The outcomes were expressed as the average number of $\mathrm{Ki}-67$ positive cells per $\mathrm{mm}^{3}$.

FJ-C positive cells along the RMS were counted manually with supporting Image J1.46r software (Wayne Rasband National Institutes of Health, USA). Their number was expressed as the mean number of cells per section.

Differences in the number of dividing and dying cells between control and irradiated animals were analyzed by the one-way ANOVA test, followed by the Sidak multiple comparison test and unpaired Student's t-test.

\section{Results}

\section{Morphological observation of proliferating cells}

Light microscopic observation of Ki-67 immunohistochemical labelling showed obvious qualitative changes in the density of proliferating cells within the RMS of both groups of rats irradiated in adulthood. Low density of Ki-67 positive cells was the most striking in the group of animals without time for recovery following finishing the radiation (Fig. 1). At this level of investigation, no changes in proliferation activity were seen in the group of animals irradiated as juvenile and left to survive to adulthood.

Subsequent quantitative analysis of Ki-67 positive cells was consistent with the morphological observation. In rats irradiated as adults we have observed the statistically highly significant decrease of the number of dividing cells in all part of the RMS immediately after the finishing of radiation (Fig. 2A). After 2 weeks of survival, the proliferation activity slightly increased, but it was still markedly reduced in comparison with control animals (Fig. 2A). In this group of rats, the decrease in the number of $\mathrm{Ki}-67$ positive cells was the most prominent in the RMS vertical arm, which is characteristic by the highest amount of proliferating cells under physiological conditions.

The number of proliferating cells in the RMS of 
rats irradiated as juvenile was after two months of survival (i.e. in adulthood) slightly decreased, mainly in the vertical arm of the migratory pathway. However, this decrease did not reach statistical significance (Fig. 2B).
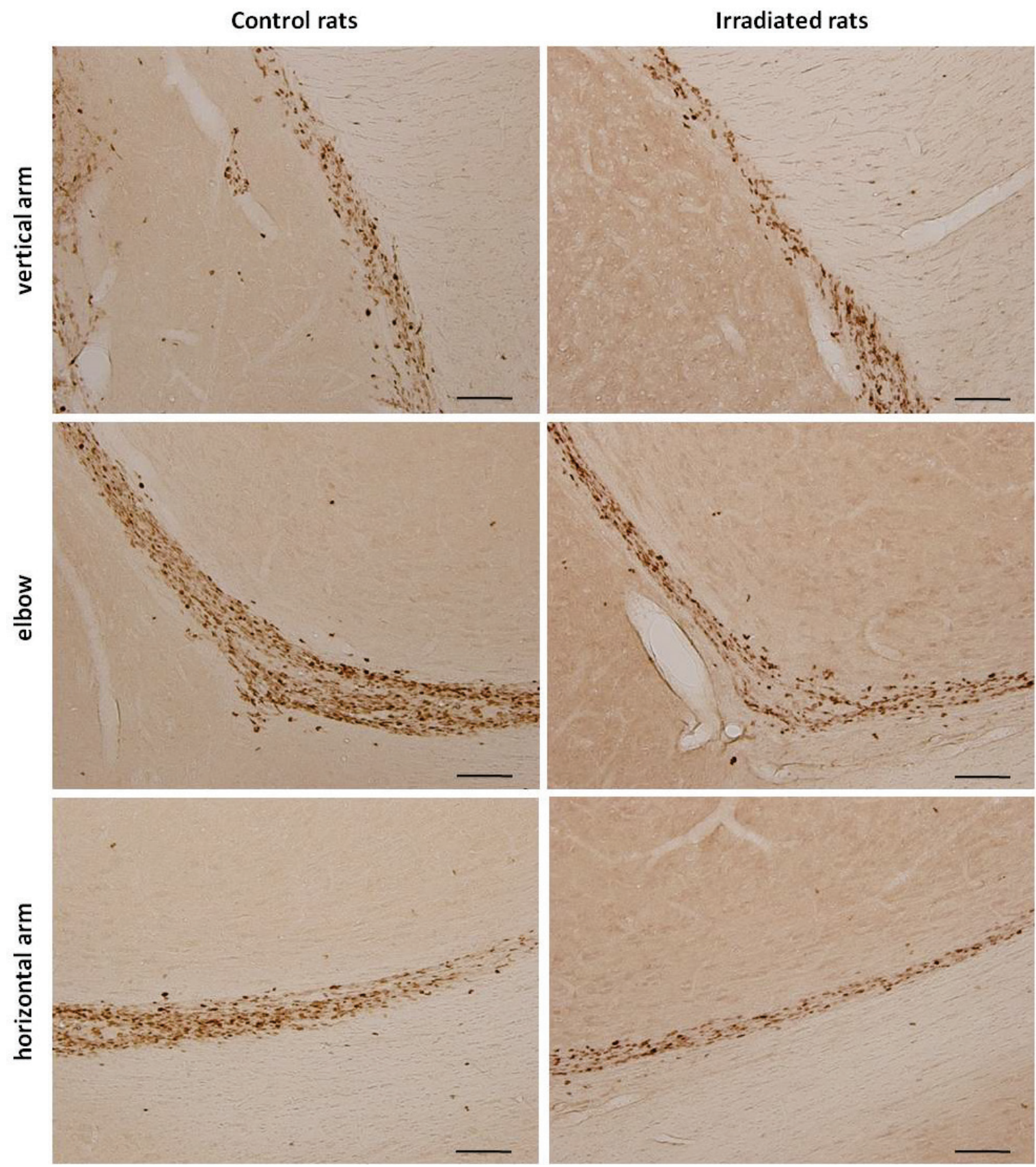

Fig. 1. Ki-67 immunohistochemistry. Representative photomicrographs illustrate the density of proliferating cells within the RMS individual parts: in the vertical arm, elbow and horizontal arm of adult control and adult irradiated rats without survival. Bars $=100 \mu \mathrm{m}$.

\section{Morphological observation of dying cells}

In the groups of rats irradiated in adulthood, the reduction of the number of dividing cells was accompanied by an increase of progenitor cells dying in the RMS. However, this increase was only very slight and did not show any statistical significance (Fig. 3A).

Interestingly, the exposure of juvenile rats to the MWR strikingly affected cell death even in adulthood.
An increased amount of FJ-C positive cells in the RMS of these animals was apparent already when observed in the fluorescence microscope (Fig. 4). Quantitative evaluation has shown that two months after irradiation, the number of dying cells in the RMS of irradiated rats was about twice as high as in control animals of the same age (Fig. 3B). 
A
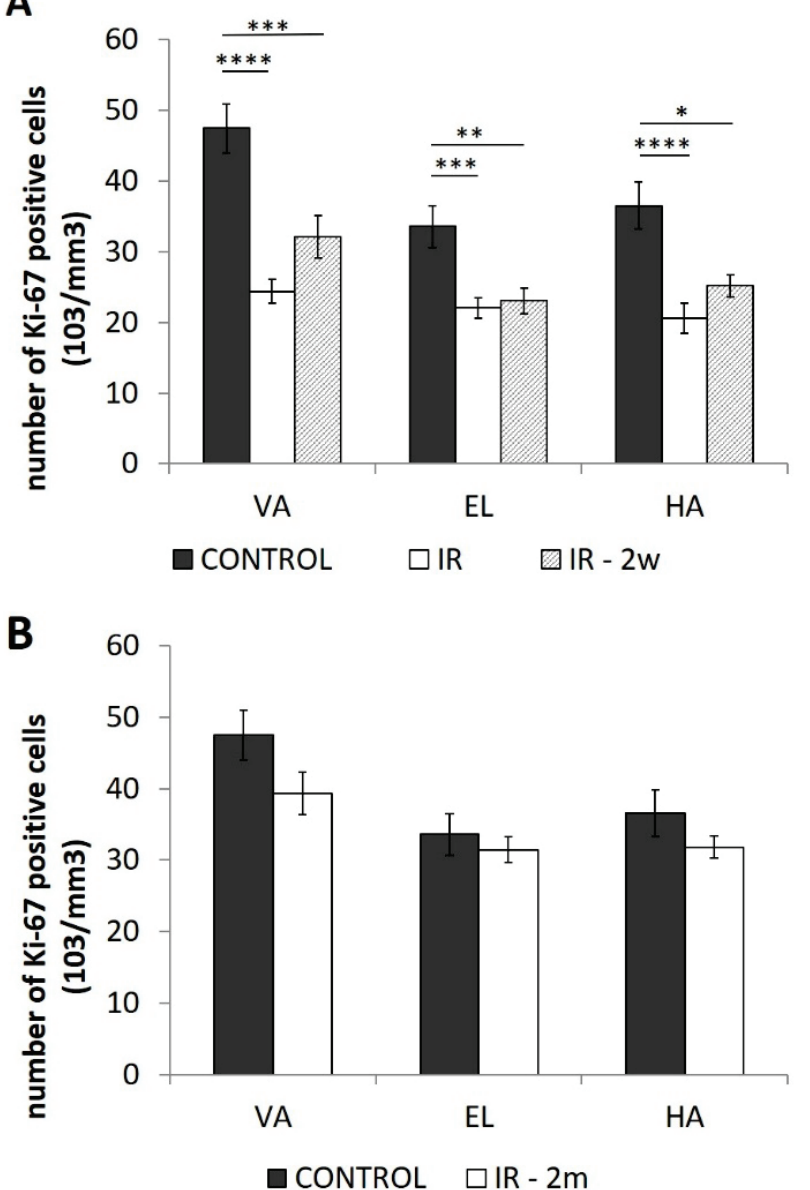

Fig. 2. The number of Ki-67 positive cells in the vertical arm (VA), elbow (EL) and horizontal arm (HA) of the RMS of adult control and irradiated rats. (A) The proliferation is decreased in all parts of the RMS of rats irradiated in adulthood (IR). After 2 weeks survival the decrease remained highly significant only in the RMS vertical arm (IR-2w). (B) Non-significant decrease of proliferation after 2 months survival of rats irradiated as juvenile (IR-2m). Statistical significance of differences between groups: $* \mathrm{p}<0.05 ; * * \mathrm{p}<0.01 ; * * * \mathrm{p}<0.001 ; * * * * \mathrm{p}<0.0001$.

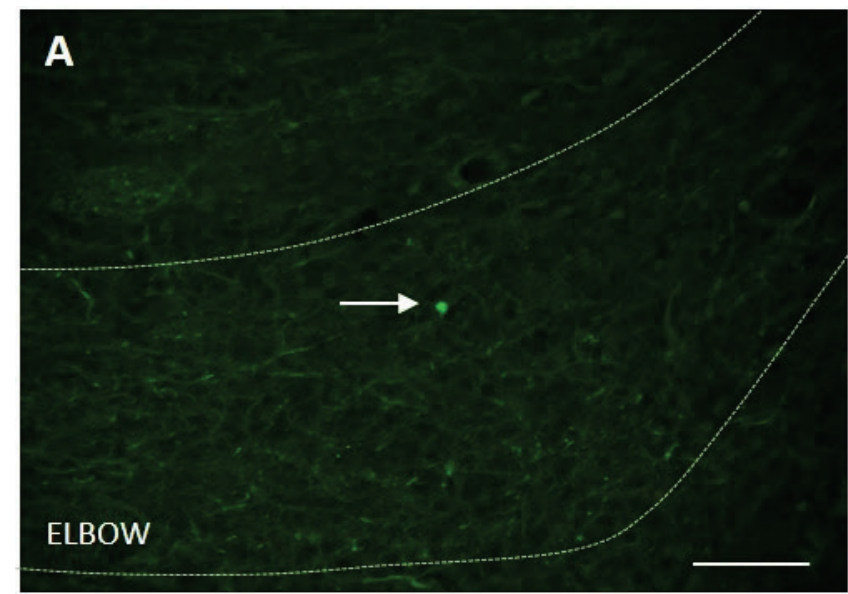

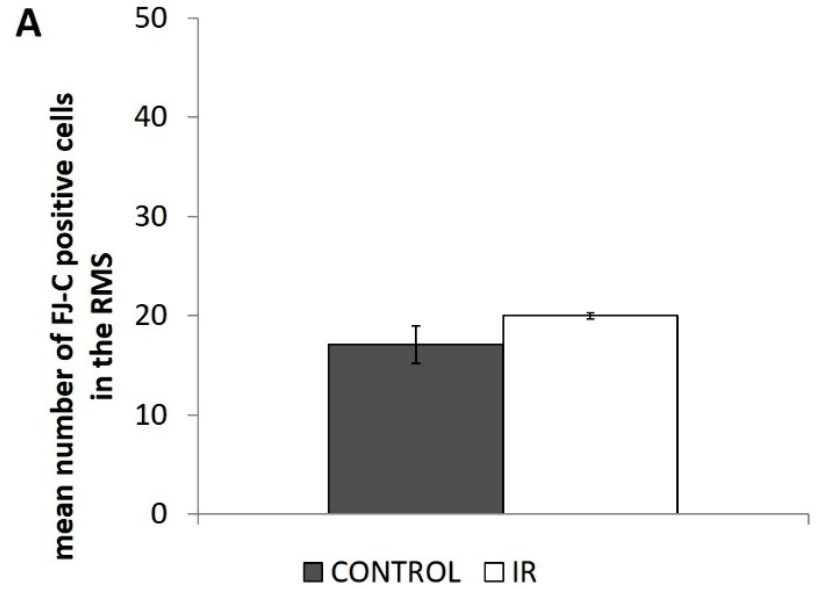

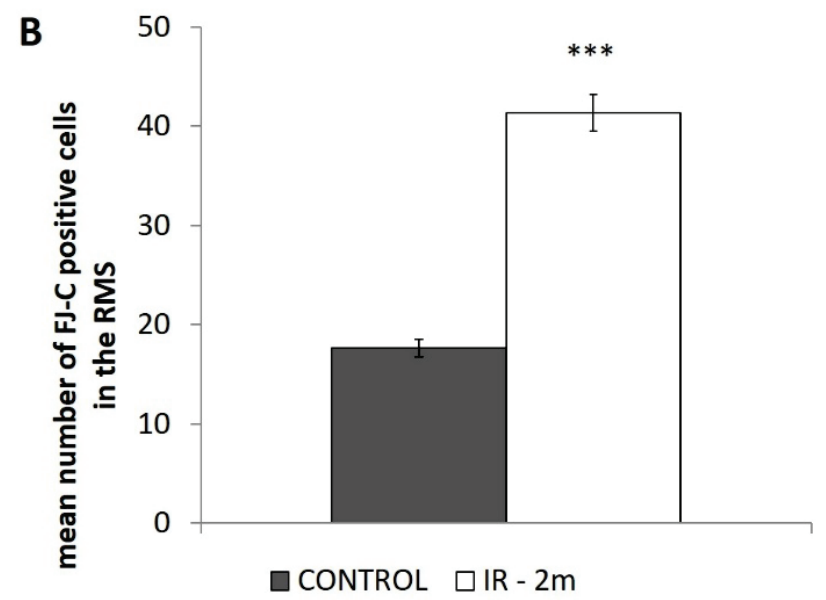

Fig. 3. The number of FJ-C positive cells in the RMS. (A) Exposure of adult rats (IR) to MWR did not cause significant changes in cell dying. (B) Statistically highly significant increase of the number of dying cells in the RMS of rats irradiated as juvenile (IR-2m). $* * * p<0.001$.

Fig. 4. Representative photomicrographs of FJ-C staining in the vertical arm (VA) elbow of the RMS of adult control rat (A) and of the rat irradiated as juvenile (B). Note the high density of labeled cells (arrows) in the RMS of irradiated rat. Bar=50 $\mu \mathrm{m}$. 


\section{Behavioral test}

The results of behavioral analysis of rats irradiated as juvenile revealed a distinct effect of the MWR on some of the parameters monitored in the light/dark test (Fig. 5A, B). MWR exposed rats spent significantly less time in the head-out position when compared to the control group. They spent significantly more time in the open field $(\mathrm{p} \leq 0.05)$ and significantly less time in the hide box than control animals $(\mathrm{p} \leq 0.05)$ (Fig. 5A). Latency to emerge into the light compartment was lower in irradiated rats in comparison with control animals. However, this difference was not statistically significant. The number of head-outs of MWR exposed rats was significantly lower than in control group. ( $\mathrm{p} \leq 0.01)$ (Fig. 5B). In the MWR group, an increase in the number of fecal boluses was observed compared with the control group, however without statistical significance.

A
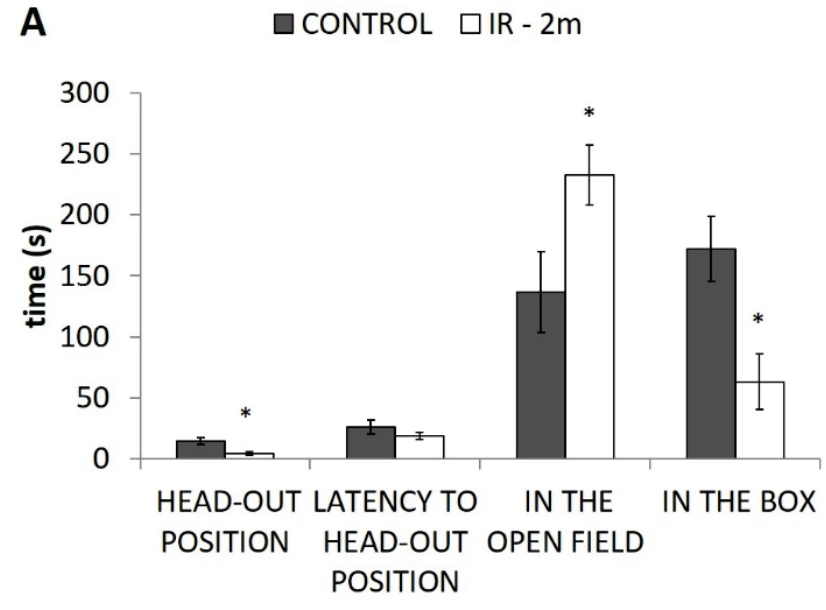

B aCONTROL $\square \mathrm{IR}-2 \mathrm{~m}$

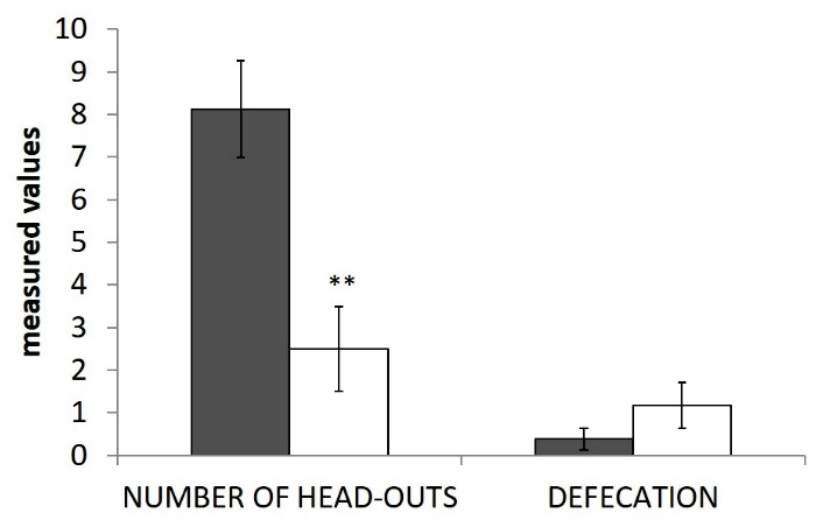

Fig. 5. Behavioral scores for measured parameters in the light/dark box. Irradiated rats (IR-2m) spent more time in the open field; less time in the head-out position (A) and showed less frequent "head outs" than control rats (B). The data are represented as mean $\pm \mathrm{SEM}$. $* \mathrm{p}<0.05 ; * * \mathrm{p}<0.01$.

\section{Discussion}

The purpose of this study was to investigate the influence of long-term exposure to MWR on processes of neurogenesis in the pathway serving for migration of SVZ generated neuroblasts toward the OB - the RMS. In rats irradiated as juvenile, we have also studied the potential long-lasting effect of MWR on animals' behavior.

\section{Morphological changes}

It is well established that stress can modify individual processes of postnatal neurogenesis (Joels et al. 2007). Morphological findings obtained in this study have shown that exposure to MWR induces significant alterations in neurogenesis, such as decreased proliferation activity and increased cell dying in the RMS in dependence on the age of animals and survival time after the irradiation.

The effect of stress on postnatal neurogenesis is mostly manifested by suppressed cell proliferation in both of major neurogenic regions, the SVZ-RMS and hippocampus (Račeková et al. 2009, Heine et al. 2004). Quantitative analysis of $\mathrm{Ki}-67$ positive cells in the migratory pathway of rats irradiated as adults confirmed the negative effect of MWR on proliferation, which was revealed by the statistically highly significant decrease of the number of dividing cells within the RMS at the end of 3-weeks long irradiation. After two weeks of survival, a slight increase in proliferation was observed. However, the number of dividing cells remained still significantly smaller than in control animals. This recovery, despite its modesty, indicates that the effect of MWR on cell proliferation is reversible.

Supporting our data, reduction in the number of Ki-67 positive cells was reported in the proliferative zone of the hippocampal gyrus dentatus following gamma radiation (Kee et al. 2002). Moreover, the authors of this work revealed parallel changes in the number of dividing cells when the endogenous marker Ki-67 as well as the exogenous marker 5-bromo-2-deoxyuridine was used. These results indicate that radiation does not change either expression level of Ki-67 or cell cycle.

Generally, it can be assumed that changes in the number of proliferating cells result from altered proliferation or from their survival. We have found the deepest decrease of Ki-67 positive cells in the RMS directly after the finishing of the irradiation and the concurrent slight increase of dying cells number. 
It suggests that the role of cell death on suppressed proliferation appears to be subtle.

The MWR impact on proliferation and cell death in rats that were irradiated as juveniles and survived until reaching adulthood was manifested rather differently. The long-term effect of radiation did not concern proliferation activity, as the number of dividing cells did not considerably decrease after two months of survival. However, exposure to MWR induced the long-lasting enhancement of cell death within the RMS of irradiated animals. It suggests that the long-lasting effect of radiation is more likely manifested by affected cell survival than reduced proliferation of cells. A comparison of the extent of increase in cell dying with the extent of proliferation, using the same method of quantification, would be of interest.

The exact cellular pathways mediating an effect of electromagnetic radiation on neurogenesis are still unknown. Further studies are required to reveal the mechanism by which MWR influence the proliferation and cell death within the migratory pathway.

\section{Behavioral changes}

Alterations in neurogenesis observed in rats exposed to MWR as juvenile were accompanied by noticeable changes in animals' behaviour. The results are generally in line with other findings suggesting that neurogenesis appears to be very sensitive to many types of stressors (including different kinds of radiation) particularly when stress occurs during the early postnatal period (Aldad et al. 2012, Korosi et al. 2012).

Behavioral analysis in the light/dark test revealed that these rats displayed locomotor hyperactivity and increased risk assessment in adulthood. The light/dark test was originally intended to test anxiety-like behavior in rodents (Bourin and Hascoet 2003). Later studies showed that some of monitored parameters also reflect locomotor and exploratory behavior (Arrant et al. 2013, Okuliarova et al. 2016). For instance, the time spent in light and dark compartments of the testing apparatus provides indices of locomotor activity. Regarding our results, exposure to MWR enhanced locomotor activity, as it significantly reduced the time spent in the hide box and increased the time spent in the open field. We suppose that decreased time of head-out position or highly significantly decreased number of head-outs found in irradiated rats reflects decreased risk assessment. Hyperactivity in the light-dark test was reported following prenatal exposure of mice to radiofrequency radiation (Aldad et al. 2012). Long-term exposure of newborn wild type mice to high frequency EMF (close to mobile phones) mildly influenced motor activity in the open field testing (Vožeh et al. 2007). In another experimental paradigm of early life stress, induced by daily parental separation, locomotor hyperactivity was observed (Bock et al. 2017).

Similar to our findings, delayed hyperactivitylike behavior was demonstrated following chronic exposure of mice to electromagnetic radiation from smartphones (Choi and Choi 2016). By providing recovery for 4 weeks following an 11-week-long period of exposure to a radiation, the authors observed hyperactivity-like behavior without affecting hippocampal progenitor cell proliferation. Significant increase in locomotor activity has been also shown following the exposure of rats to the same frequency of radiation $(2.45 \mathrm{GHz})$ as was used in our experiment. Consistent to our results, the locomotor hyperactivity persisted throughout the course of a 22-week sequence of exposures to radiation (Mitchell et al. 1997). In addition, the results of epidemiological study provided by Divan et al. (2008) have shown that children who had possible prenatal or postnatal exposure to cell phone use had behavioral difficulties such as emotional and hyperactivity problems around the age of school entry. These reports together with our findings led to the suggestion that long-lasting survival after chronic exposure to MWR can induce recovery in proliferation, but not in animal behavior.

How is locomotor hyperactivity related to alterations of neurogenesis occurring in the RMS after irradiation? New interneurons generated in the SVZ contribute to odor discrimination and play an essential role in regulating olfactory information sent by principal neurons to higher brain regions (Breton et al. 2009). Indeed, some difference in olfactory function has been observed following focal irradiation of the SVZ by gamma rays (Lazarini et al. 2009). In the experimental paradigm of forebrain ionizing irradiation an evidence of behavioral changes other than olfactory was also obtained (Iwata et al. 2008). Three months after fractionated irradiation, the rats displayed abnormal locomotor activity and social interaction deficits. The authors suggested that behavioral abnormalities may be associated with marked reduction of neurogenesis, caused by irradiation, observed in the major neurogenic areas. Another explanation of this issue could be that locomotor hyperactivity following MWR exposure may be 
associated with impaired olfaction of irradiated rats as a consequence of enhanced cell dying in their RMS. This idea is supported by some recent investigations that have shown substantial olfactory deficit in patients with attention deficit hyperactivity disorder (Karsz et al. 2008).

In conclusion, we have shown that long-term exposure to MWR led to significant reduction of neurogenesis in the RMS of adult rats. To our best knowledge, this is the first report demonstrating prolonged effect of MWR on the RMS of rats irradiated as juvenile. In addition to enhanced cell dying within the RMS, these animals displayed locomotor hyperactivity in adulthood. Further investigation of molecular and cellular mechanisms underlying morphological and behavioral changes in irradiated rats would contribute to understanding the hazardous effects of MWR on the brain.

\section{Conflict of Interest}

There is no conflict of interest.

\section{Acknowledgements}

This study was supported by grants VEGA 1/0060/18, $2 / 0069 / 15$ and $2 / 0159 / 17$.

\section{References}

ALDAD TS, GAN G, GAO XB, TAYLO HS: Fetal radiofrequency radiation exposure from 800-1900 Mhz-rated cellular telephones affects neurodevelopment and behavior in mice. Sci Rep 2: 312, 2012.

ALTUNKAYNAK BZ, ALTUN G, YAHYAZADEH A, KAPLAN AA, DENIZ OG, TÜRKMEN AP, ÖNGER ME, KAPLAN S: Different methods for evaluating the effects of microwave radiation exposure on the nervous system. J Chem Neuroanat 75: 62-69, 2016.

ARRANT AE, SCHRAMM-SAPYTA NL, KUHNA CM: Use of the light/dark test for anxiety in adult and adolescent male rats. Behav Brain Res 256: 119-127, 2013.

BOCK J, BREUER S, POEGGEL G, BRAUN K: Early life stress induces attention-deficit hyperactivity disorder (ADHD)-like behavioral and brain metabolic dysfunctions: functional imaging of methylphenidate treatment in a novel rodent model. Brain Struct Funct 222: 765-780, 2017.

BOURIN M, HASCOET M: The mouse light/dark box test. Eur J Pharmacol 463: 55-65, 2003.

BRETON-PROVENCHER V, LEMASSON M, PERALTA MR, SAGHATELYAN A: Interneurons produced in adulthood are required for the normal functioning of the olfactory bulb network and for the execution of selected olfactory behaviors. J Neurosci 29: 15245-15257, 2009.

BRUNJES PC, ARMSTRONG AM: Apoptosis in the rostral migratory migratory stream of the developing rats. Dev Brain Res 92: 219-222, 1996.

CHOI YJ, CHOI YS: Effects of electromagnetic radiation from smartphones on learning ability and hippocampal progenitor cell proliferation in mice. Osong Public Health Res Perspect 7: 12-17, 2016.

DIVAN HA, KHEIFETS L, OBEL C, OLSEN J: Prenatal and postnatal exposure to cell phone use and behavioral problems in children. Epidemiology 19: 523-529, 2008.

FINNIE JW, CHIDLOW G, BLUMBERGS PC, MANAVIS J, CAI Z: Heat shock protein induction in foetal mouse brain as a measure of stress after whole of gestation exposure to mobile telephony radiofrequency fields. Pathology 41: 276-279, 2009.

HAO YH, ZHAO L, PENG RY: Effects of microwave radiation on brain energy metabolism and related mechanisms. Mil Med Res 17: 2-4, 2015.

HEINE VM, MASLAM S, ZARENO J, JOELS M, LUCASSEN PJ: Suppressed proliferation and apoptotic changes in the rat dentate gyrus after acute and chronic stress are reversible. Eur J Neurosci 19: 131-144, 2004.

IWATA Y, SUZUKI K, WAKUDA T, SEKI N, THANSEEM I, MATSUZAKI H, MAMIYMA T, UEKI T, MIKAWA S, SASAKI T, SUDA S, YAMAMOTO S, TSUCHIYA KJ, SUGIHARA G, NAKAMURA K, SATO K, TAKEI N, HASHIMOTO K, MORI N: Irradiation in adulthood as a new model of schizophrenia. PLoS One 3 : e2283, 2008.

JOELS M, KARST H, KRUGERS HJ, LUCASSEN PJ: Chronic stress: implications for neuronal morphology, function and neurogenesis. Front Neuroendocrinol 28: 72-96, 2007. 
KARSZ FR, VANCE A, ANDERSON VA, BRANN PG, WOOD SJ, PANTELIS C, BREWER WJ: Olfactory impairments in child attention-deficit/hyperactivity disorder. J Clin Psychiatry 69: 1462-1468, 2008.

KEE N, SIVALINGAM S, BOONSTRA R, WOJTOWICZ JM: The utility of Ki-67 and BrdU as proliferative markers of adult neurogenesis. J Neurosci Methods 114: 97-105, 2002.

KHURANA VG, HARDELL L, EVEEERAERT J, BORTKIEWICZ A, CARLBERG M, AHONEN M: Epidemiological evidence for a health risk from mobile phone base station. Int J Occup Environ Health 16: 263-267, 2010.

KOROSI A, NANINCKA EFG, OOMENB CA, SCHOUTENA M, KRUGERS H, FITZSIMONS C, LUCASSENA PJ: Early-life stress mediated modulation of adult neurogenesis and behavior. Behav Brain Res 227: 400-409, 2012.

LAZARINI F, MOUTHON MA, GHEUSI G, DE CHAUMONT F, OLIVO-MARIN JC, LAMARQUE S, ABROUS DN, BOUSSIN FD, LLEDO PM: Cellular and behavioral effects of cranial irradiation of the subventricular zone in adult mice. PloS One 4: e7017, 2009.

LLEDO PM, MERKLE FT, ALVAREZ-BUYLLA A: Origin and function of olfactory bulb interneuron diversity. Trends Neurosci 8: 392-400, 2008.

LOIS C, ALVAREZ-BUYLLA A: Long-distance neuronal migration in the adult mammalian brain. Science 264: 1145-1148, 1994.

LUSKIN MB: Restricted proliferation and migration of postnatally generated neurons derived from the forebrain subventricular zone. Neuron 11: 173-189, 1993.

MENEZES JR, SMITH CM, NELSON KC, LUSKIN MB: The division of neuronal progenitor cells during migration in the neonatal mammalian forebrain. Mol Cell Neurosci 6: 496-508, 1995.

MITCHELL DS, SWITZER WG, BRONAUGH EL: Hyperactivity and disruption of operant behavior in rats after multiple exposures to microwave radiation. Radio Sci 12: 263-271, 1997.

ODACI E, BAS O, KAPLAN S: Effects of prenatal exposure to a $900 \mathrm{MHz}$ electromagnetic field on the dentate gyrus of rats: a stereological and histopathological study. Brain Res 1238: 224-229, 2008.

OKULIAROVÁ M, MOLČAN L, ZEMAN M: Decreased emotional reactivity of rats exposed to repeated phase shifts of light-dark cycle. Physiol Behav 156: 16-23, 2016.

ORENDÁČOVÁ J, ORENDÁČ M, MOJŽIŠ M, LABUN J, MARTONČÍKOVÁ M, SAGANOVÁ K, LIEVAJOVÁ K, BLAŠKO J, ABDIOVÁ H, GÁLIK J, RAČEKOVÁ E: Effects of short-duration electromagnetic radiation on early postnatal neurogenesis in rats: Fos and NADPH-d histochemical studies. Acta Histochem 113: 723-728, 2011.

ORENDÁČOVÁ J, ORENDÁČ M, RAČEKOVÁ E, MARŠALA J: Neurobiological effects of microwave exposure: a review focused on morphological findings in experimental animals. Arch Ital Biol 145: 1-12, 2007.

ORENDÁČOVÁ J, RAČEKOVÁ E, ORENDÁČ M, MARTONČÍKOVÁ M, SAGANOVÁ K, LIEVAJOVÁ K, ABDIOVÁ H, LABUN J, GÁLIK J: Immunohistochemical study of postnatal neurogenesis after whole-body exposure to electromagnetic fields: evaluation of age- and dose-related changes in rats. Cell Mol Neurobiol 29: 981-990, 2009.

RAČEKOVÁ E, LIEVAJOVÁ K, DANKO J, MARTONČÍKOVÁ M, FLEŠÁROVÁ S, ALMAŠIOVÁ V, ORENDÁČOVÁ J: Maternal separation induced alterations of neurogenesis in the rat rostral migratory stream. Cell Mol Neurobiol 29: 811-819, 2009.

TOMORI Z, KREKULE I, KUBÍNOVÁ I: Dissector program for unbiased estimation of particle number, numerical density and mean volume. Image Anal Stereol 20: 119-130, 2001.

VOJTÍSEK M, KNOTKOVÁ J, KASPAROVÁ L, SVANDOVÁ E, MARKVARTOVÁ V, TŮMA J, VOZEH F, PATKOVÁ J: Metal, EMF, and brain energy metabolism. Electromagn Biol Med 28: 188-193, 2009.

VOŽEH F, DONĚK A, CENDELÍN J, KORELUSOVÁ I, VRBA J: Study of high-frequency electromagnetic field effect on some somatic and neuro-behavioral characteristics in healthy and neurodefective mice. Environmentalist 27: 501-504, 2007.

WINNER B, KOHL Z, GAGE FH: Neurodegenerative diseases and adult neurogenesis. Eur J Neurosci 33: 1139-1151, 2011. 